\title{
A MATHEMATICAL MODEL FOR DIRECT EVAPORATIVE COOLING AIR CONDITIONING SYSTEM
}

\author{
J. R. Camargo, \\ Universidade de Taubaté \\ Departamento de Engenharia Mecânica \\ Rua Daniel Danelli, s/n \\ 12060-440; Taubaté; São Paulo; Brasil \\ rui@mec.unitau.br \\ C. D. Ebinuma, \\ Universidade Estadual Paulista - UNESP, FEG \\ Departamento de Energia \\ Rua Ariberto Pereira da Cunha, 333 \\ 12500-000; Guaratinguetá; São Paulo; Brasil \\ S. Cardoso, \\ Universidade de Taubaté \\ Departamento de Engenharia Mecânica \\ Rua Daniel Danelli, s/n \\ 12060-440; Taubaté; São Paulo; Brasil

\begin{abstract}
Air conditioning systems are responsible for increasing men's work efficiency as well for his comfort, mainly in the warm periods of the year. Currently, the most used system is the mechanical vapor compression system. However, in many cases, evaporative cooling system can be an economical alternative to replace the conventional system, under several conditions, or as a pre-cooler in the conventional systems. It leads to a reduction in the operational cost, comparing with systems using only mechanical refrigeration. Evaporative cooling operates using induced processes of heat and mass transfer, where water and air are the working fluids. It consists in water evaporation, induced by the passage of an air flow, thus decreasing the air temperature. This paper presents the basic the principles of operation for the direct evaporative cooling system and the mathematical development of the equations of thermal exchanges, allowing the determination of the effectiveness of saturation. It also presents some results of experimental tests in a direct evaporative cooler that take place in the Air Conditioning Laboratory at the University of Taubaté Mechanical Engineering Department, and the experimental results are used to determinate the convective heat transfer coefficient and to compare with the mathematical model.
\end{abstract} \\ principles of the evaporative cooling process for human thermal comfort,
}

\section{INTRODUCTION}

Evaporative cooling operates using induced processes of heat and mass transfer, where water and air are the working fluids. It consists, specifically, in water evaporation, induced by the passage of an air flow, thus decreasing the air temperature. When water evaporates into the air to be cooled, simultaneously humidifying it, that is called direct evaporative cooling (DEC) and the thermal process is the adiabatic saturation. When the air to be cooled is kept separated from the evaporation process, and therefore is not humidified while it is cooled, it is called indirect evaporative cooling (IEC). The main characteristic of this process is the fact that it is more efficient when the temperatures are higher, that means, when more cooling is necessary for thermal comfort. It has the additional attractiveness of low energy consumption and easy maintenance. Due to use total airflow renewal, it eliminates the recirculation flow and proliferation of fungi and bacteria, a constant problem in conventional air conditioning systems.

Several authors dedicated their researches to the development of direct evaporative cooling systems. Watt (1963) developed the first serious analyses of direct and indirect evaporative systems, Leung (1995) presents an experimental research of the forced convection between an air flow and an inner surface of a horizontal isosceles triangular duct, Maclaine-Cross and Banks (1983) developed equations to model evaporative regenerative heat exchanger, Halasz (1998) presented a general dimensionless mathematical model to describe all evaporative cooling devices used today (cooling water towers, evaporative condensers of fluid, air washes, dehumidification coils, etc); Cardoso, Camargo and Travelho (2000) developed a research where a thermal balance study for direct and indirect cooling systems was developed; Camargo and Ebinuma (2002) presented the principles of operation for direct and indirect evaporative cooling systems and the mathematical development of thermal exchanges equations, Dai and Sumathy (2002) researched a cross-flow direct evaporative cooler, in which the wet durable honeycomb paper constitutes the packing material, Liao and Chiu (2002) developed a compact wind tunnel to simulate evaporative cooling pad-fan systems and tested two alternative materials. Al-Sulaiman (2002) evaluated the performance of three natural fibers (palm fiber, jute and luffa) used as wetted pads in direct evaporative coolers. Hasan and Sirén (2003) investigated the performance of two evaporatively heat exchangers operating under similar conditions of air flow and inlet water temperatures

This paper develops a mathematical model for direct evaporative cooling system and presents some experimental tests results in a direct evaporative cooler that take place in the Air Conditioning Laboratory at the University of Taubaté Mechanical Engineering Department, located in the city of Taubaté, State of São Paulo, Brazil. 
CIÊNCIA/SCIENCE

\section{DIRECT EVAPORATIVE COOLING}

The principle underlying direct evaporative cooling is the conversion of sensible heat to latent heat. Non-saturated air is cooled by heat and mass transfer increases by forcing the movement of air through an enlarged liquid water surface area for evaporation by utilizing blowers or fans. Some of the sensible heat of the air is transferred to the water and becomes latent heat by evaporating some of the water. The latent heat follows the water vapor and diffuses into the air (Watt and Brown, 1997).

Figure 1 shows a schematic direct evaporative cooling system.

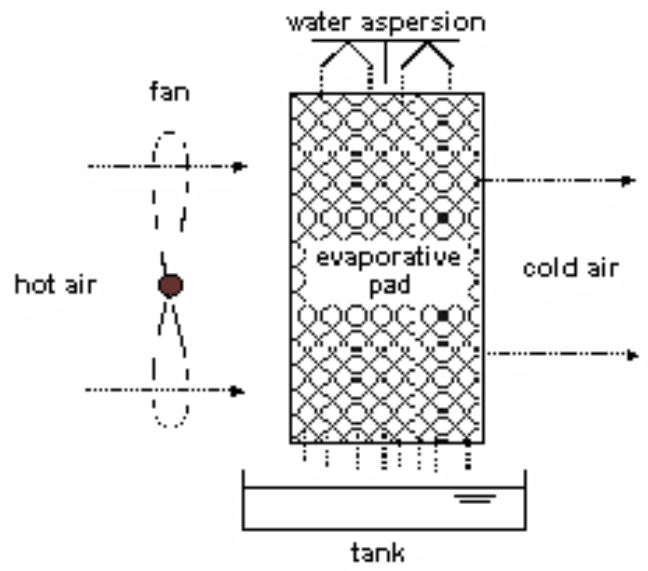

Figure 1 - Direct evaporative cooler (DEC)

In a DEC, the heat and mass transferred between air and water decreases the air dry bulb temperature (DBT) and increases its humidity, keeping the enthalpy constant (adiabatic cooling) in an ideal process. The minimum temperature that can be reached is the wet bulb temperature (WBT) of the incoming air. The effectiveness of this system is defined as the rate between the real decrease of the DBT and the maximum theoretical decrease that the DBT could have if the cooling were $100 \%$ efficient and the outlet air were saturated.

Practically, wet porous materials or pads provide a large water surface in which the air moisture contact is achieved and the pad is wetted by dripping water onto the upper edge of vertically mounted pads.

\section{MATHEMATICAL MODEL}

In the study of the psychrometric process dry air is considered as a single gas characterized by an average molecular mass equal to 28.9645 . In this work the humid air is considered as a mixture of two gases: the dry air and water vapor.

Considering the flow of humid air close to a wet surface, according to Fig. (2), the heat transfer will occur if the surface temperature $T_{s}$ is different from the draft temperature $T$. If the absolute humidity (concentration) of the air close the surface $w_{s}$ is different from the humidity of the draft $w$ a mass transfer will also occur.

The elementary sensible heat is

$\delta \mathrm{Q}_{\mathrm{s}}=\mathrm{h}_{\mathrm{c}} \mathrm{dA}\left(\mathrm{T}_{\mathrm{s}}-\mathrm{T}\right)$ where $h_{c}$ is the convective heat transfer coefficient, $A$ is the area of the heat transfer surface, $T_{s}$ is the surface temperature and $T$ is the bulk temperature.
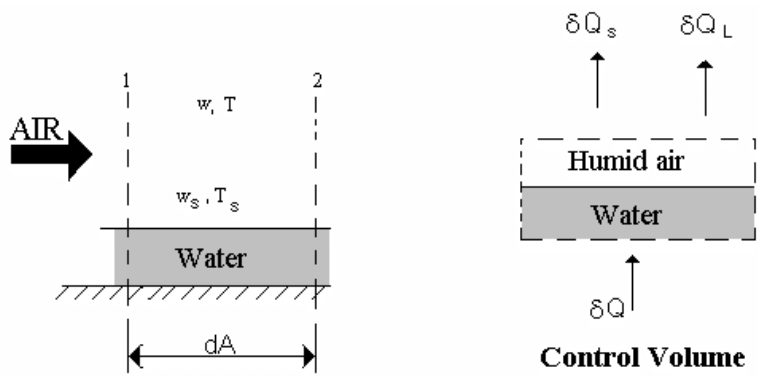

Figure 2 - Schematic direct evaporative cooler

The $h_{c}$ coefficient is determined from the Nusselt number $(\mathrm{Nu})$ expressed as a function of the Reynolds number (Re) and Prandtl number (Pr).

In a similar way the rate of water vapour transfer $d m_{V}$ between the draft and the air close to the surface will be

$\mathrm{dm}_{\mathrm{v}}=\mathrm{h}_{\mathrm{m}} \rho_{\mathrm{a}} \mathrm{dA}\left(\mathrm{w}_{\mathrm{s}}-\mathrm{w}\right)$

where $h_{m}$ is the mass transfer coefficient by convection and $\rho_{\mathrm{a}}$ is the density of the water.

By analysis of the interface air-liquid, the latent heat $\delta Q_{L}$ is determined by the energy conservation law.

$\delta \mathrm{Q}_{\mathrm{L}}=\delta \mathrm{Q}-\delta \mathrm{Q}_{\mathrm{s}}=\mathrm{h}_{\mathrm{Lvs}} \mathrm{dm} \mathrm{v}_{\mathrm{v}}$

where $\delta Q$ is the flow of total heat and $h_{L V S}$ is the specific enthalpy of vaporization of the water at surface temperature. Rearranging Eqs. (1), (2) and (3), the total differential heat flow is

$\delta Q=\left[h_{c}\left(T_{s}-T\right)+\rho_{a} h_{L v s} h_{m}\left(w_{s}-w\right)\right] d A$

Equation (4) indicates that the total heat transfer is the result of a combination of a portion originating from temperature difference and other portion originating from the difference of the absolute humidities. The total heat is caused by two potentials and these potentials can be combined by the Lewis relationship so that the total heat flow will be expressed by a single potential that is the enthalpy difference between the air close to the wet surface and the air free current.

Using the specific enthalpy of the mixture as the sum of the individual enthalpies (Moreira, 1999, p.99) gives

$\mathrm{h}_{\mathrm{s}}-\mathrm{h}=\left(\mathrm{h}_{\mathrm{sa}}-\mathrm{h}_{\mathrm{a}}\right)+\left(\mathrm{w}_{\mathrm{s}} \mathrm{h}_{\mathrm{vs}}-\mathrm{wh}_{\mathrm{v}}\right)$

where $h_{V S}$ is the vapor enthalpy at surface temperature, $h_{s a}$ is the enthalpy of the leaving air, $h_{a}$ is the air enthalpy and $h_{v}$ is the vapor enthalpy. With the hypothesis that air and vapor are perfect gases it follows that

$\mathrm{h}_{\mathrm{s}}-\mathrm{h}=\mathrm{c}_{\mathrm{pu}}\left(\mathrm{T}_{\mathrm{s}}-\mathrm{T}\right)+\mathrm{h}_{\mathrm{vs}}\left(\mathrm{w}_{\mathrm{s}}-\mathrm{w}\right)$

where the humid specific heat is $\mathrm{c}_{\mathrm{pu}}=\mathrm{c}_{\mathrm{pa}}+\mathrm{wc}_{\mathrm{pv}}$. 


\section{CIÊNCIA/SCIENCE}

$\mathrm{C}_{\mathrm{pa}}$ is the constant pressure specific heat of the air and $\mathrm{C}_{\mathrm{pv}}$ is the constant pressure specific heat of the vapor. In the standard environmental conditions $\mathrm{C}_{\mathrm{pa}}=1,006 \mathrm{~kJ} / \mathrm{kg}$ $\mathrm{K}$ and $\mathrm{C}_{\mathrm{pv}}=1,805 \mathrm{~kJ} / \mathrm{kg} \mathrm{K}$.

Therefore

$\mathrm{T}_{\mathrm{s}}-\mathrm{T}=\frac{\left(\mathrm{h}_{\mathrm{s}}-\mathrm{h}\right)-\mathrm{h}_{\mathrm{vs}}\left(\mathrm{w}_{\mathrm{s}}-\mathrm{w}\right)}{\mathrm{c}_{\mathrm{pu}}}$

Combining Eq. (4) and Eq. (7) gives

$\delta \mathrm{Q}=\frac{\mathrm{h}_{\mathrm{c}} \mathrm{dA}}{\mathrm{c}_{\mathrm{pu}}}\left[\left(\mathrm{h}_{\mathrm{s}}-\mathrm{h}\right)+\frac{\left(\mathrm{w}_{\mathrm{s}}-\mathrm{w}\right)}{\mathrm{R}_{\mathrm{Le}}}\left(\mathrm{h}_{\mathrm{Lvs}}-\mathrm{R}_{\mathrm{Le}} \mathrm{h}_{\mathrm{vs}}\right)\right]$

where $R_{L e}$ is the Lewis relationship, a dimensionless number expressed as

$$
\mathrm{R}_{\mathrm{Le}}=\frac{\mathrm{h}_{\mathrm{c}}}{\mathrm{h}_{\mathrm{m}} \mathrm{C}_{\mathrm{pu}} \rho}
$$

In the above deduction the density of the humid air was approximated by the density of the dry air. Taking the Lewis relationship as being unitary, gives $\left(\mathrm{h}_{\mathrm{Lvs}}-\mathrm{h}_{\mathrm{vs}}\right) \approx \mathrm{h}_{\mathrm{Ls}}$. It is also verified that the term $\left(\mathrm{w}-\mathrm{w}_{\mathrm{s}}\right) \mathrm{h}_{\mathrm{Ls}}$ is usually negligible in the presence of difference of the specific enthalpies $\left(h_{s}-h\right)$, so that only the first term inside brackets is significant. In the same way, the total heat flow is caused by the difference of specific enthalpies of the air and of the saturated air close to the wet surface and is given by

$\delta \mathrm{Q}=\frac{\mathrm{h}_{\mathrm{c}} \mathrm{dA}}{\mathrm{c}_{\mathrm{pu}}}\left(\mathrm{h}_{\mathrm{s}}-\mathrm{h}\right)$

The sensible heat transferred is

$\delta \mathrm{Q}_{\mathrm{s}}=\mathrm{m}_{\mathrm{a}} \mathrm{c}_{\mathrm{pu}} \mathrm{dT}$

where $m_{a}$ is the air mass flow. Therefore by combining Eq. (11) with Eq. (1) gives

$$
h_{c} d A\left(T_{s}-T\right)=m_{a} c_{p u} d T
$$

which can be integrated, resulting in

$$
\frac{\mathrm{h}_{\mathrm{c}}}{\mathrm{m}_{\mathrm{a}} \mathrm{c}_{\mathrm{pu}}} \int_{0}^{\mathrm{A}} \mathrm{dA}=\int_{\mathrm{T}_{1}}^{\mathrm{T}_{2}} \frac{\mathrm{dT}}{\left(\mathrm{T}_{\mathrm{s}}-\mathrm{T}\right)}
$$

The integration yields

$$
1-\frac{T_{1}-T_{2}}{T_{1}-T_{s}}=\exp \left(-\frac{h_{c} A}{m_{a} c_{p u}}\right)
$$

\section{J. R. Camargo et al. A Mathematical Model...}

The effectiveness of a direct evaporative cooling equipment is defined as

$\varepsilon=\frac{\mathrm{T}_{1}-\mathrm{T}_{2}}{\mathrm{~T}_{1}-\mathrm{T}_{\mathrm{s}}}$

then

$\varepsilon=1-\exp \left(-\frac{\mathrm{h}}{\mathrm{A}}\right)$

Analysing the Eq. (15) it is verified that an effectiveness of $100 \%$ corresponds to air leaving the equipment at the wet bulb temperature of entrance. This requires a combination of large area of heat transfer and a high heat transfer coefficient and low mass flow.

It is also observed that the effectiveness is constant if the mass flow is constant since it controls directly and indirectly the value of the parameters on the Eq. (16).

\section{EXPERIMENTAL WORK}

Experiments were developed during the months of December/2002, January/2003 and February/2003 in the Air Conditioning Laboratory at the University of Taubaté Mechanical Engineering Department, located in the city of Taubaté, State of São Paulo, Brazil. Performance tests were carried on an air conditioning device by direct evaporative cooling, model ECOBRISA20 manufactured by VIVA Equipamentos Ltda. The evaporative device was instaled in a room of $6.50 \mathrm{~m}$ of length, $5.30 \mathrm{~m}$ of width and $2.90 \mathrm{~m}$ of height and the following parameters were monitored: outdoor air humidity and temperature, evaporative cooler inlet air humidity and temperature, evaporative cooler outlet air humidity and temperature, water temperature inside the supplying tubes, water temperature at the evaporative cooling reservoir, evaporative pad surface temperature, evaporative cooler outlet air speed.

Air temperatures and humidity were monitored using thermal-hygrometers HT-208 model from Gubintec, with precision of $0.1^{\circ} \mathrm{C}$ and $0.1 \% \mathrm{RH}$. Evaporative pad surface and water temperature were monitored by digital thermometers from SUMMIT, SDT20 CE model and the market trades SALCAS, SALV TERM 700C model, with precision of $0.1^{\circ} \mathrm{C}$. Air speed was monitored by a 9 point measure matrix using portable anemometers type turbine, PWM model from Dwyer Instruments Inc, USA with precision of $0.1 \mathrm{~m} / \mathrm{s}$.

The ECOBRISA20 utilizes an evaporative pad with $610 \times 335 \times 152 \mathrm{~mm}$ that is composed of a cellulose material impregnated with a thermosetting resin to prevent deterioration, shrinkage or sagging. The media incorporates an internal geometry of transverse alternating flutes and the arrangement increases cooling efficiency by causing turbulence while the air is travelling through the media (GLACIER-COR, 1999) and provides about $400 \mathrm{~m}^{2}$ of evaporative surface area per $\mathrm{m}^{3}$ of media. 


\section{CIÊNCIA/SCIENCE}

Dowdy and Karabash (1987) presents a correlation to determinate the convective heat transfer coefficients in a rigid cellulose evaporative media:

$\mathrm{Nu}=0.10\left(\frac{1_{\mathrm{e}}}{1}\right)^{0.12} \operatorname{Re}^{0.8} \operatorname{Pr}^{1 / 3}$

where $l_{e}$ is the characteristic length and $l$ is the pad thickness.

$1_{\mathrm{e}}=\frac{\vartheta}{\mathrm{A}}$

where $\vartheta$ is the volume occupied by the cellulose media and $A$ is the total wetted surface area.

The following air properties are used: $\mathrm{k}=0.0263$ $\mathrm{W} / \mathrm{m}^{\circ} \mathrm{C} ; \operatorname{Pr}=0.708 ; \mathrm{C}_{\mathrm{pu}}=1033 \mathrm{~J} / \mathrm{kg}^{\circ} \mathrm{C}$ and $\mathrm{v}=15.7 \times 10^{-6}$ $\mathrm{m}^{2} / \mathrm{s}$.

The evaporative cooler provides air flow variation by the of fan rotation. Figure 3 presents a variation of the cooling effectiveness as a function of air speed at the outlet face of the evaporative device. This figure shows the curve plotted from the data presented at the evaporative pads manufacturer catalogue (Glacier-cor) and the data obtained from tests.

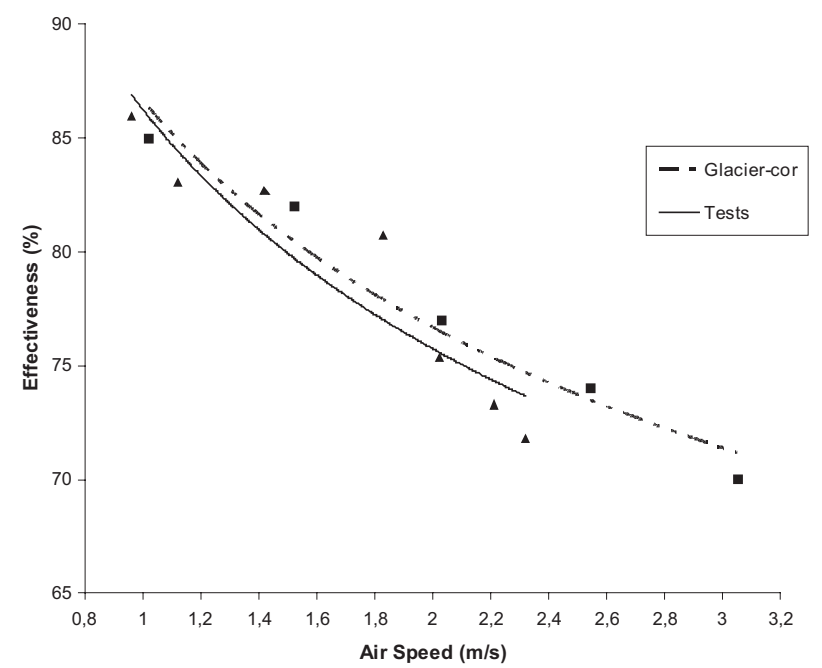

Figure 3 - Effectiveness x Air Speed

Table 1 shows the resulting convective heat transfer coefficient for several air velocities calculated from Eq.(16).

Table 1 - Convective heat transfer coefficient for several air speeds.

\begin{tabular}{|c|c|c|c|}
\hline $\begin{array}{c}\mathrm{V} \\
{[\mathrm{m} / \mathrm{s}]}\end{array}$ & $\begin{array}{c}\dot{\mathrm{m}} \\
{[\mathrm{kg} / \mathrm{s}]}\end{array}$ & $\begin{array}{c}\mathrm{Re} \\
{[1]}\end{array}$ & $\begin{array}{c}\mathrm{h}_{\mathrm{c}} \\
{\left[\mathrm{W} / \mathrm{m}^{20} \mathrm{C}\right]}\end{array}$ \\
\hline 0.96 & 0.203 & 153 & 35.28 \\
\hline 1.12 & 0.233 & 178 & 35.49 \\
\hline 1.42 & 0.297 & 226 & 43.05 \\
\hline 2.02 & 0.419 & 322 & 57.12 \\
\hline 2.21 & 0.458 & 353 & 611.32 \\
\hline 2.32 & 0.480 & 370 & 63.81 \\
\hline
\end{tabular}

J. R. Camargo et al. A Mathematical Model...

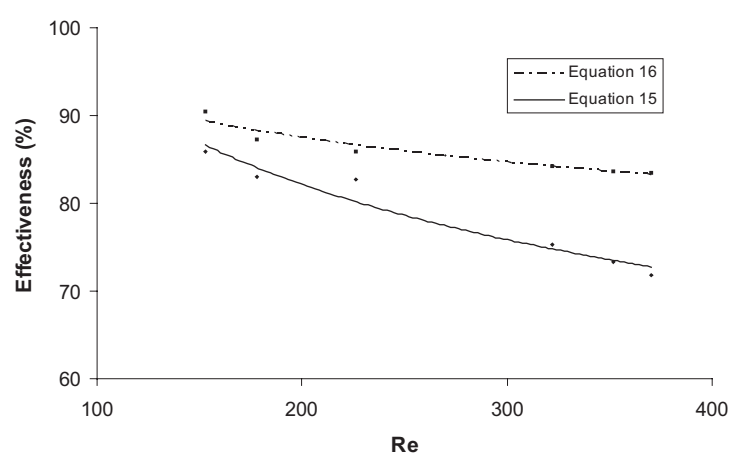

Figure 4 - Effectiveness x Reynolds number

Figure 4 shows the comparison between the effectiveness calculated from the Eq. (15) and Eq. (16) as function of the Reynolds number.

\section{CONCLUSION}

This paper presents a mathematical model for a direct evaporative cooling air conditioning system that is obtained by writing the energy conservation equation for an elementary control volume and analyzing the heat and mass transfer between the humid air and the water. The resulting equation allows to determinate the DEC effectiveness and compares it with the experimental results, according to Fig. 4 which the curve concerning to the Eq. 15 was determined by the temperature values measured in the inlet and outlet air flow and the curve referring to the Eq. 16 was determined using the mass air flow and the convective transfer coefficient obtained from the Eq. 17. 


\section{REFERENCES}

Al-Sulaiman, F., 2002, "Evaluation of the Performance of Local Fibers in Evaporative Cooling", Energy Conversion \& Management, Elsevier Science Ltd, p. 2267-2273.

Camargo, J. R.; Cardoso, S.; Travelho J. S., 2000, "Condicionamento de Ar por Resfriamento Evaporativo", Anais do $9^{\circ}$ Congreso Chileno de Ingenieria Mecânica, IV Congreso Nacional de Energia, COCIM-CONAE 2000, Valparaiso, Chile.

Camargo, J. R.; Ebinuma, C. D., 2002, “A mathematical model for direct and indirect evaporative cooling air conditioning systems", Proceedings of the $9^{\text {th }}$ Brazilian Congress of Thermal Engineering and Sciences, CONEM 2002, UFPB, João Pessoa, PB.

Dai, Y. J.; Sumathy, K., 2002, "Theoretical Study on a Cross-flow Direct Evaporative Cooler Using Honeycomb Paper as Packing Material", Applied Thermal Engineering,, 22, Elsevier Science Ltd, p.1417-1430.

Dowdy, J. A.; Karabash, N. S., 1987, "Experimental Determination of Heat and Mass Transfer Coefficients in rigid Impregnated Cellulose Evaporative Media", ASHRAE Transactions, part 2, v. 93. p. 382-395.

GLACIER-COR CELLULOSE EVAPORATIVE COOLING PADS, 1999."Operation and Maintenance Manual”. Scottsdale, Arizona, USA.

Halaz B. A., 1998, "A General Mathematical Model of Evaporative Cooling Devices", Rev. Gén. Therm., FR, Elsevier, Paris, vol.37, p.245-255.

Hasan, A.; Sirén, K., 2003, "Performance Investigation of Plain and Finned Tube Evaporatively Cooled Heat Exchangers, Applied Thermal Engineering, Elsevier Science Ltd, p. 325-340.

Leung, C. W., 1995, "Forced Convection Inside Horizontal Isosceles Triangular Ducts", IMechE Conference Transactions, Mechanical Engineering Publications Ltd, London, p.117-121.

Liao, C.; Chiu, K., 2002., "Wind Tunnel Modeling the System Performance of Alternative Evaporative Cooling Pads in Taiwan Region, Building and Environment, Elsevier Science Ltd, p. 177-187.

Maclaine-Cross, I. L. and Banks, P. J., 1983, “A general theory of wet surface heat exchangers and its application to regenerative evaporative cooling", Journal of Heat Transfer, vol.103, n.3, pp. 579-585.

Moreira, J. R. S., 1999, "Fundamentos e Aplicações da Psicrometria”, RPA Editorial Ltda, São Paulo.

Watt, J. R., 1963, "Evaporative Air Conditioning", The Industrial Press, New York, 300p.

Watt, J. R. and Brown, W. K., 1997, "Evaporative air conditioning handbook", $3^{a}$ ed., The Fairmont Press, Inc., Lilburn, GA. 